\title{
ATRAVESSAMENTOS DE UM CORPO-MEMÓRIA: O ATO DE CRIAR COMO DEVIR-LEMBRANÇA
}

\author{
CROSSES OF A MEMORY BODY: \\ THE ACT OF CREATING HOW TO BECOME REMEMBER
}

Roseany Karimme Silva Fonseca ${ }^{1}$

\begin{abstract}
Resumo: Este trabalho propõe os atravessamentos possíveis de um corpo localizado pela memória. Partindo do texto "O Ato de Criação" de Gilles Deleuze, no qual este autor aponta a ideia de espaçotempo, além de descrever o criador como alguém que produz por necessidade. Pesquisa-se no presente trabalho o ato de criar como devir-lembrança. São explicitadas as semelhanças e as diferenças entre os conceitos de memória e lembrança, tendo como base a obra "Espaços da Recordação", da autora Aleida Assmann. Por meio de uma abordagem metodológica de pesquisa comparativa, que possibilita intersecções entre ambas as obras, objetiva-se compreender como este corpo-memória atravessa e é atravessado no processo de criação artística por meio da relação com o tempo e o espaço, estejam estes localizados no passado ou no presente.
\end{abstract}

Palavras-chaves: Corpo; memória; devir-lembrança.

Abstract: This work proposes the possible crossings of a body located by memory. Starting from the text "The Act of Creation" by Gilles Deleuze (1999), in which this author points out the idea of space-time, in addition to describing the creator as someone who produces out of necessity. In the present work, the act of creating as becoming-remembrance is researched. The similarities and differences between the concepts of memory and remembrance are explained, based on the work "Spaces of Recollection", by the author Aleida Assmann (2011). Through a methodological approach of comparative research, which allows intersections between both works, the objective is to understand how this body-memory crosses and is crossed in the process of artistic creation through the relationship with time and space, whether these are located in the past or in the present. Keywords: Body; memory; becoming- memory.

\section{Introdução}

O corpo configura-se como uma instância que produz memória; não apenas memórias físicas ou sensoriais, como também as memórias afetivas. Cada corpo possui uma história, uma origem - individual, familiar, social - às quais constituem-se como determinantes para a aquisição de suas trocas com outros corpos e com o mundo. $\mathrm{Na}$ arte, o corpo pode ser indutor de diversas possibilidades criativas, seja por meio do teatro, da performance, da dança, entre outros. Mas o corpo que produz arte, produz em um espaço-tempo - não apenas em um, como em vários. E desta afirmação, surgem os questionamentos que norteiam o presente trabalho: no ato de criar, que espaço-tempo seria este - ou estes? O processo de criação artística acompanha um possível deslocamento das ideias de espaço e tempo?

Este trabalho propõe os atravessamentos possíveis de um corpo localizado pela memória. Partindo do texto "O Ato de Criação" de Gilles Deleuze ${ }^{2}$, na qual este autor aponta a ideia de espaço-tempo, além de descrever o criador como alguém que produz por necessidade. Pesquisa-se

\footnotetext{
${ }^{1}$ Programa de Pós-Graduação em Artes - PPGARTES/UFPA.

${ }^{2}$ Gilles Deleuze (1925-1995) foi um filósofo francês. Seu principal campo de interesse, além do campo da Filosofia, é a criação artística como modo de produção de subjetividade.
} 
no presente trabalho o ato de criar como devir-lembrança. São explicitadas as semelhanças e as diferenças entre os conceitos de memória e lembrança, tendo como base a obra "Espaços da Recordação", da autora Aleida Assmann ${ }^{3}$. Por meio de uma abordagem metodológica de pesquisa comparativa, que possibilita intersecções entre ambas as obras, objetiva-se compreender como este corpo-memória atravessa e é atravessado no processo de criação artística por meio da relação com o tempo e o espaço, estejam estes localizados no passado ou no presente.

\section{O ato de criação}

No texto intitulado $O$ Ato de Criação, o filósofo Gilles Deleuze (1999) atenta para a importância do que ele chama de necessidade criadora, muito além do prazer em criar: o criador não como aquele ser que trabalha somente pelo prazer, mas também (e principalmente) por uma necessidade. Embora o texto seja voltado para um encontro entre o cinema e a filosofia, o que se apresentam aqui são as ideias sobre os processos criativos de forma mais ampla. Deleuze cita um limite comum a todas as formas de criação: o espaço-tempo: "o limite que é comum a todas essas séries de invenções, invenções de funções, invenções de blocos de duração/movimento, invenção de conceitos, é o espaço-tempo." (DELEUZE, 1999, p. 04).

$\mathrm{O}$ autor supracitado também expande a ideia de blocos de movimentos em outras áreas que não são somente a filosofia ou o cinema, mas a ideia de arte como um todo. Há um paralelo entre arte e ciência, que neste caso não se colocam como forças antagônicas:

O que vocês inventam não são conceitos — isso não é de sua alçada —, mas blocos de movimento/ duração. Se fabricamos um bloco de movimento/duração, é possível que façamos cinema. Não se trata de invocar uma história ou de recusá-la. Tudo tem uma história. A filosofia também conta histórias. Histórias com conceitos. O cinema conta histórias com blocos de movimento/duração. A pintura inventa um tipo totalmente diverso de bloco. Não são nem blocos de conceitos, nem blocos de movimento/duração, mas blocos de linhas/cores. A música inventa um outro tipo de bloco, também todo peculiar. Ao lado de tudo isso, a ciência não é menos criadora. Eu não vejo tantas oposições entre as ciências e as artes. (DELEUZE, 1999, p. 03-04).

Pensar na distribuição do ato criativo em blocos de movimento possibilita definir qual (ou quais) a forma/conteúdo deste processo. De Vivar et al. (2017) percebem a postura Deleuziana como um pensamento sobre

o papel da arte sobre o que nós chamamos aqui de potência de viver, isto é, um modo específico de tentar compreender os efeitos produzidos pelos objetos estéticos cujos impactos se refletem - como num jogo de espelhos em novas formas de subjetividade que não cessam de proliferar linhas de fuga responsáveis por escapar da normatividade dos dispositivos. (DE VIVAR et al., 2017, p. 02, ênfases originais).

Em outro momento, o texto deleuziano trata a ideia como parte do pensamento e não da comunicação; a ideia como algo que vem antes do conceito e de seu campo de atuação, a filosofia. A comunicação, por sua vez, é definida pelo autor como a transmissão/propagação de informações. Há também uma relação de ambivalência entre o ato de resistência e a obra de arte: todo ato de

\footnotetext{
${ }^{3}$ Aleida Assmann é uma autora, professora e pesquisadora alemã. Seus trabalhos transitam entre a literatura e os temas da memória social, coletiva e cultural.
} 
resistência não é obra de arte, embora, de certa maneira, esta faça parte dele. Assim como toda obra de arte não é um ato de resistência e, no entanto, de certo modo, acabe sendo.

Trata de escrever sobre a arte com a finalidade de rastrear no interstício de um pensamento não conceitual os traços da diferença como estratégia política, pois, para Deleuze, a arte é o procedimento por meio do qual o sujeito relaciona-se com a intensidade dos afetos. (DE VIVAR et al., 2017, p. 03).

A potência afetiva imbuída na arte é o canal pelo qual Deleuze aponta para uma filosofia da diferença. Outros autores, como o filósofo Baruch Espinosa ${ }^{4}$, destacam a importância do afeto enquanto construção de sentido para a obra artística. Gleizer (2005), em seu livro dedicado à abordagem dos afetos na obra de Espinosa, propõe estas relações:

O corpo se atualiza e se individua por meio das composições de relações que estabelece com o ambiente, transmissões de movimento e repouso que não cessam de ocorrer. Essas composições são intensivas, estando, dessa forma, intrinsecamente relacionadas a uma dinâmica afetiva (GLEIZER, 2005, p. 45).

\section{Espaços da recordação}

Na obra Espaços da Recordação, a autora Aleida Assmann (2011) destrincha diversos lugares da memória, estejam eles nos espaços, no tempo ou na história. Neste livro, propõe-se a diferença entre memória, lembrança e recordação, colocando estes três termos como fundamentais para a localização dos indivíduos e suas culturas.

Assmann discorre acerca dos recipientes da memória. Cita um exemplo da memória como arca, ou seja, um espaço onde se guardam as recordações: uma espécie de arquivo, onde os registros podem ser novamente acessados. Para isto, a autora aborda modos de recordação: a memória funcional (habitada) e a memória cumulativa (inabitada). A primeira assegura a identidade do grupo, é seletiva, liga passado, presente e futuro e está vinculada a um portador (grupo, instituição ou indivíduo); já a memória histórica, ou cumulativa, separa completamente passado, presente e futuro, não depende de um portador específico e não é seletiva: ambas se colocam em um patamar igualmente importante. Pode-se inferir que a memória não está apenas vinculada a ideia de tempo, mas a um espaço ocupado. Estes espaços incluem intersecções, aqui abordadas pela perspectiva de um corpo que carrega a memória e está envolvido em um processo artístico. Estes atravessamentos serão melhor abordados no próximo item, dedicado à proposta de um corpo-memória.

\section{Atravessamento(s) do corpo-memória}

O corpo-memória aqui destacado é um corpo envolvido na cena. $\mathrm{O}$ corpo do artista cênico - seja ele ator, dançarino, artista circense ou performer - é um corpo que produz expressões outras, para o trabalho artístico. No entanto, anteriormente ao trabalho artístico, o corpo cotidiano se configura enquanto estrutura de memórias, que afeta/é afetada por instâncias que remetem ao ato de lembrar. $\mathrm{O}$ autor José Gil propõe o termo corpo paradoxal, no qual as percepções de interno e externo se dissolvem, criando novas inscrições e espaços, "como se recobrissem as coisas com um invólucro semelhante à pele: o espaço do corpo é a pele que se prolonga no espaço, a pele tornada espaço" (GIL, 2005, p. 47).

\footnotetext{
${ }^{4}$ Baruch Espinosa (1632-1677) foi um filósofo racionalista holandês dentro da chamada Filosofia Moderna. Foi um pesquisador da ideia de afetos, sendo estes considerados encontros entre os seres que determinam sua potência de agir.
} 
Como produção de signos e significados, o corpo cênico é capaz de criar símbolos a partir de si mesmo para a arte. Na introdução do capítulo dedicado às escritas do corpo, Aleida Assmann (2011) cita os autores Marcel Proust: "Pernas e braços estão repletos de recordações adormecidas" e Samuel Beckett: "Não há como escapar do ontem porque ontem já nos deformou ou foi por nós deformado" para a compreensão de que tempo/espaço se inscrevem na linguagem corporal. De acordo com Greiner (2005), o corpo se torna um espaço determinado pela constante impermanência e reconstrução das induções expressadas e recebidas por meio da afetação dos campos de percepção sensível. Não apenas o corpo daquele que se apresenta, mas também daquele que compartilha o momento da ação. O corpo-artista é aquele em que este momento des(re)estabilizante tende a perdurar. Dessa experiência nascem metáforas complexas que serão desencadeadores de outras experiências sucessivas que irão desestabilizar outros corpos e ambientes (GREINER, 2005).

Neste sentido, o corpo-memória configura-se como um corpo que lembra - sendo esta relação é intrínseca a sua existência e o devir-lembrança como a ação deste corpo ao lembrar, enquanto produção de movimentos artísticos, relações e afetos. No ato de criar, este corpo acessa memórias físicas e mentais; espaços concretos e metafóricos, tempos cronológicos e afetivos.

O espaço que experenciamos [...] é o espaço do céu, ou do mar, ou da paisagem, ou de uma cidade vista de um edifício alto, o espaço construído das ruas, dos prédios vistos de fora ou experienciados no seu interior, o espaço dos mapas, dos planos, cosmografias e geometrias, espaços interestelares, o espaço possuído pelos objetos ou reclamados pelos países ou ainda o espaço devotado aos deuses. [...] O espaço nos oferece de uma variedade de formas e de relações entre espaço e lugar em que os lugares não podem ser separados de seu contexto de experiência. (SANTAELLA, 2007, p. 164).

Propor este corpo-memória enquanto unidade cênica é potencializar movimentos de criação por meio da instância que evoca as lembranças, estas reorganizadas de acordo com os processos artísticos das quais fazem parte. Leonardelli (2011) afirma que os processos de criação requerem uma reorganização dos corpos que estão envolvidos, bem como uma organização de memórias e saberes, convergindo nas demandas específicas de cada percurso.

O corpo-memória deste texto é um corpo atravessado não apenas externamente pelas cicatrizes, mas internamente pelo processo de dor e do que levou a estas novas inscrições. As cicatrizes apresentam-se como as lembranças inscritas e marcadas - daquilo que passou e passa pelo corpo. Um corpo que se recria e descobre outras possibilidades, por meio da fragilidade: "pensar o corpo não como função ou instrumento de trabalho, mas como sujeito, como unidade mínima da cena. Pensar o corpo como ser, como mistério da existência, composto de muitas camadas." (ALMEIDA, 2016, p. 39). Refletir sobre um corpo dito frágil é compreendê-lo como aquele que sofre a ação de deixar-se afetar, receber e escutar. Quais as vozes que se ouvem quando se possibilita a fala/escuta desse corpo frágil? Certamente, são movimentos que perpassam a memória do corpo. Desta forma, o corpo-memória dialoga com a ideia de potência:

A fragilidade torna transparente, poroso, o limiar entre vida e não vida. A consciência dessa liminaridade confere um tipo muito especial de poder, um poder com lastro [...] um poder que é (sem nenhum possuidor), um poder que prefiro chamar de potência. A potência de um corpo que padece é uma potência íntegra, nascida do reconhecimento e da aceitação de sua sombra. Há de se pensar o corpo em vida em sua irrevogável mortalidade. Sem essa dimensão o corpo é pura exterioridade. É simples. A vida precisa de 
polaridades para que haja movimento, e em Artes da Cena, o movimento entre interioridade e exterioridade, entre subjetividade e objetividade, é fundamental. (ALMEIDA, 2016, p. 40-41, ênfases da autora).

Assim, compreende-se que o corpo não é uma instância que tem a memória, no sentido de posse, mas que é a memória no sentido de integralidade e que está entre seu interior e a exterioridade das relações com os outros e com o mundo, onde ocorrem trocas. As autoras Beth Lopes e Verônica Almeida propõem visões deste corpo; seja na performance ou na cena de modo mais geral, ele está sempre imbricado nesta fronteira:

O discurso do performer constitui sua linguagem a partir do contexto simbólico da sua memória, ligando materialmente, inconsciente e ideologia. O tempo, passado, presente e futuros são totalmente intercambiáveis. $\mathrm{Na}$ multiplicação dos tempos e espaços dos fragmentos da memória, se criam dobras que se dobram sobre si mesma numa sequência de remissões ao conjunto que as lembranças pertencem. Criar uma narrativa com a linguagem corporal significa agregar uma quantidade de fatos sobrepostos da memória que correm em diferentes direções. Sendo assim, os discursos da memória são sempre portais de inscrição de outros saberes, tempos e modos de existência [...] o espaço da memória é um lugar de trânsito de ideias e sentimentos, um lugar de subjetividades, de revelação da interioridade do performer na razão direta da sua exterioridade. (LOPES, 2009, p. 135).

É nessa fronteira, nesse espaço liminar, que a cena está constantemente a se desfazer e a se refazer. Cena líquida? Solve, coagula, solve e coagula... Como diriam os alquimistas. Cena a se desconstruir e a se reconstruir em potência, pois é esse o movimento da vida. A vida se alimenta da vida. (ALMEIDA, 2016, p. 63).

Isto posto, os atravessamentos de um corpo-memória no processo de criação artística não se encontram apenas na própria história deste corpo, mas nas relações tecidas com outros corpos, evidenciando a importância do tempo passado para compreender o presente/futuro e também a importância do espaço interno para compreender o que existe fora. Assim, corroborase tanto a posição de Assmann em relação aos movimentos da memória, quanto a noção Deleuziana acerca do ato criativo: "eu diria o seguinte: no limite de todas as tentativas de criação, existem espaços-tempos” (DELEUZE, 1999, p. 05).

\section{Considerações finais}

Este trabalho partiu de uma abordagem de pesquisa comparativa para dialogar com autores(as) que pensam o tempo e o espaço como proposições metafóricas para o ato de criar e lembrar. Partindo de Deleuze e Assmann, considera-se uma relação entre o corpo criador por meio da memória e por uma atividade denominada devir-lembrança. $\mathrm{O}$ devir-lembrança aqui surge como este processo de resgate de um corpo que lembra, onde o corpo não apenas possui a capacidade de lembrar, como constitui-se como a própria lembrança.

Embora Deleuze cite o cinema em seu texto, neste texto o ato de criar é visto de forma mais ampla e direcionado para o corpo da cena, propondo interlocuções outras: para o encontro de um organismo com suas memórias físicas e psíquicas. Conclui-se que o ato de criar envolve um processo a partir de um tempo-espaço que não é unicamente concreto, mas o tempo-espaço da experiência, fator fundamental para a existência humana. 


\section{Referências}

ALMEIDA, Verônica Fabrini Machado de. Corpo e Artes da Cena. In: Corpo e processos de criação nas artes cênicas [recurso eletrônico] / Marcilio de Souza Vieira, Robson Carlos Haderchpek. - Natal, RN: EDUFRN, 2016.

ASSMANN, Aleida. Espaços da recordação: formas e transformações da memória cultural. Campinas/SP: UNICAMP, 2011.

DELEUZE, Gilles. O ato de criação. Folha de São Paulo, v. 27, 1999.

DE VIVAR, Rodrigo Diaz et al. A Potência de Viver: Deleuze e a Arte. Psicologia \& Sociedade, v. 29, p. 1-8, 2017.

GIL, José. Movimento total: o corpo e a dança. São Paulo: Iluminuras, 2005.

GLEIZER, Marcos André. Espinosa e a afetividade humana. Zahar, 2005

GREINER, Christine. O corpo: pistas para estudos indisciplinares. São Paulo: Annablume, 2005.

LEONARDELLI, Patricia. Corpo memória, cena-palavra: dramaturgia e depoimento pessoal. In: Anais do XII Congresso Internacional da ABRALIC. Curitiba: ABRALIC. 2011.

LOPES, Beth. A performance da memória. Sala Preta, v. 9, p. 135-145, 2009.

SANTAELLA, Lucia. Linguagens líquidas na era da mobilidade. São Paulo: Paulus, 2007.

\section{Sobre a autora}

Roseany Karimme Silva Fonseca. Mestranda do PPGARTES/UFPA, na linha de Poéticas e Processos de Atuação em Artes. Vinculada à Associação de Pesquisa e Pós-Graduação em Artes Cênicas/ABRACE. Escritora. Atriz e Colaboradora em Pesquisa e Montagem Cênica pela ETDUFPa. Graduada em Psicologia e Especialista em Psicopedagogia.

E-mail: rose.karimme@gmail.com. 